\title{
Cellular dosimetry of strontium-90 using the Monte Carlo code MCNPX, detection and X-ray microanalysis
}

\author{
N. Hocine ${ }^{1 \text { a }}$, D. Farlay ${ }^{2,3}$, J.-M. Bertho ${ }^{1}$, G. Boivin ${ }^{2,3}$, A. Desbrée ${ }^{1}$, D. Franck ${ }^{1}$ and M. Agarande ${ }^{1}$ \\ 1 IRSN, BP17, 92260 Fontenay-aux-Roses, France. \\ 2 INSERM UMR 1033, 69008 Lyon, France. \\ 3 Université de Lyon, 69008 Lyon, France.
}

Received 3 April 2013 - Accepted 4 July 2013

\begin{abstract}
The aim of this study is to provide data that increase knowledge about the possible health effects of exposure to ${ }^{90} \mathrm{Sr}$ contaminant in drinking water. ${ }^{90} \mathrm{Sr}$ detection in the mouse bone model plays an important complementary role with computational dosimetry in these investigations. S-value (absorbed dose per unit cumulated activity) calculations using Monte Carlo (MC) simulations, ${ }^{90} \mathrm{Sr}$ detection by liquid scintillation $\beta$ counting in the femur bone and X-ray microanalysis were carried out. The present work is focused on using MCNPX and its validation at a cellular level. The cytoplasm $(\mathrm{Cy})$, nucleus $(\mathrm{N})$ and ${ }^{90} \mathrm{Sr}$ radiation source were simulated with the MC code MCNPX. Cells are assumed to be spherical, with the radii of the cell and cell nucleus ranging from 2 to $10 \mu \mathrm{m}$. The S-value (in Gy/Bq.s) calculations were provided for a ${ }^{90} \mathrm{Sr}$ source distributed uniformly in the cell nucleus or cytoplasm and for two sourcetarget combinations $(\mathrm{t} \leftarrow \mathrm{s})$. A comparison between the calculated $\mathrm{MC}$ results and the MIRD values agreed very well since the relative deviations are less than $4 \%$. The earliest results of X-ray microanalysis indicated that the ${ }^{90} \mathrm{Sr}$ was below the detection limit $(<0.1 \%)$ in the bone tissue. However, the measurements by liquid scintillation showed the presence of ${ }^{90} \mathrm{Sr}$ in the femur bone.
\end{abstract}

Keywords: cellular dosimetry / Monte Carlo code / MCNPX / ${ }^{90} \mathrm{Sr} / \mathrm{X}$-ray microanalysis

\section{Introduction}

Strontium-90 $\left({ }^{90} \mathrm{Sr}\right)$ is a radionuclide which was released in large amounts in several situations, such as the Chernobyl explosion in 1986 (UNSCEAR, 2011). ${ }^{90} \mathrm{Sr}$ decays by emitting a beta particle. It has a half-life of 28.2 years, and due to its solubility and its chemical properties, it is a long-term remnant in the environment. Many populations have been chronically exposed to low concentrations of this radionuclide, either through ingestion or through inhalation (Cooper et al., 1992). Food and drinking water are the largest sources of exposure. Once absorbed, ${ }^{90} \mathrm{Sr}$ accumulates mainly in bones (ICRP, 1993). However, low-dose ingestion of ${ }^{90} \mathrm{Sr}$ is less welldocumented. Thus, the possible health effects of exposure to ${ }^{90} \mathrm{Sr}$ contaminant in drinking water remains to be studied. We used mouse models of chronic contamination through low concentrations of ${ }^{90} \mathrm{Sr}$ in drinking water, in order to determine the cellular distribution of ${ }^{90} \mathrm{Sr}$ in the bone of mice.

The purpose of this first part of the study was to analyze the distribution of ${ }^{90} \mathrm{Sr}$ within femur bone samples using $\mathrm{X}$ ray microanalysis. This technique was used in this study to identify and localize numerous chemical elements such as calcium, phosphorus and strontium present in embedded bone

\footnotetext{
a nora.hocine@irsn.fr
}

samples, as it was shown in previous studies (Boivin et al., 2010; Doublier et al., 2011).

Moreover, understanding the potential of ionizing radiation to effect changes in cells requires knowing how much energy is deposited in the cells and tissues as a result of these emissions. This concept is referred to as the absorbed dose. Thus, it is of interest to know the absorbed dose to the bone cell for a given activity of ${ }^{90} \mathrm{Sr}$.

The medical internal radiation dose (MIRD) provides some of the tools necessary to estimate the absorbed dose at the cellular level. These tools take the form of cellular S-values (absorbed dose per unit cumulated activity).

$\mathrm{S}$-values are used to calculate the radiation dose received by a target region $t$ when the radioactivity is distributed in a source region $s$. The relation between the mean absorbed dose $\bar{D}$ to the target region and the $\mathrm{S}$-value is:

$$
\bar{D}_{(t \leftarrow s)}=\tilde{A}_{s} \cdot S_{(t \leftarrow s)}
$$

where:

- $\bar{D}_{(t \leftarrow s)}$ is the mean absorbed dose (Gy) in the target $t$ from radiation coming from the source $s$,

- $\tilde{A}_{s}$ is the cumulated activity (Bq.s) in the source region $s$, and 
- $S_{(t \leftarrow s)}$ is the mean absorbed dose in Gray per Becquerel second (Gy/Bq.s) in the target t per cumulated activity in the source $\mathrm{s}$, often referred to as the $\mathrm{S}$-factor.

In order to establish the performance of the Monte Carlo code MCNPX in this context of dosimetry at the cellular level, the calculations of S-values using Monte Carlo (MC) simulations were carried out. This early research work is focused on using MCNPX and its validation at a cellular level. Furthermore, detection of ${ }^{90} \mathrm{Sr}$ and X-ray microanalysis were carried out.

\section{Material and methods}

\subsection{S-value calculations}

S-value calculations were performed with the Monte Carlo transport code MCNPX2.5f (Pelowitz, 2005) using the Lawrence Livermore National Laboratory cross-sections taken from the library of Cullen et al. (1997). This method is based on the probability distribution function for developing the random sampling of each event and performing the evolution of the particular phenomena being studied by means of convenient statistical techniques. The capabilities of this code involve the correct simulation of the physical problem and the geometrical configuration.

$10^{3}$ histories were run, thus providing an estimated relative error of less than $1 \%$, producing reliable confidence intervals. The figure of merit (FOM) was examined through fluctuation charts to be sure that the tally used appeared to be statistically well-behaved.

The ${ }^{90} \mathrm{Sr}$ source emits beta-particles with energies in a continuum up to $0.5 \mathrm{MeV}$. Knowledge of beta-ray spectra is important as it is used as input data to MCNPX calculations. The complete radiation spectrum for ${ }^{90} \mathrm{Sr}$ is taken from Weber et al. (1989).

The cells are assumed to be spherical, with the radii of the cell and cell nucleus ranging from 2 to $10 \mu \mathrm{m}$ (see Fig. 1). The radiation source is assumed to be uniformly distributed in one of the following regions: the cytoplasm ( $\mathrm{Cy}$ ) or cell nucleus $(\mathrm{N})$. $\mathrm{Cy}, \mathrm{N}$ and the ${ }^{90} \mathrm{Sr}$ radiation source were simulated with the MC code MCNPX.

$\mathrm{S}$-values were calculated for two source-target $(t \leftarrow s)$ combinations, namely nucleus to nucleus $(\mathrm{N} \leftarrow \mathrm{N})$ and cytoplasm to nucleus ( $\mathrm{N} \leftarrow \mathrm{Cy}$ ), using the equation:

$$
S_{(t \leftarrow s)}=1.6 \times 10^{-10}\left(\frac{{ }^{*} f_{8}}{m_{t}}\right)
$$

where ${ }^{*} f_{8}$ is the value, in $\mathrm{MeV}$, of the energy deposition tally as obtained from MCNPX simulations and $m_{t}$ is the mass of the target $t$ in $g$.

\subsection{Femur samples and ${ }^{90} \mathrm{Sr}$ measurements}

The animal contamination experiments through ingestion of ${ }^{90} \mathrm{Sr}$ in drinking water used in this study were described in detail in the previous work of Synhaeve et al. (2011) carried out at the IRSN.

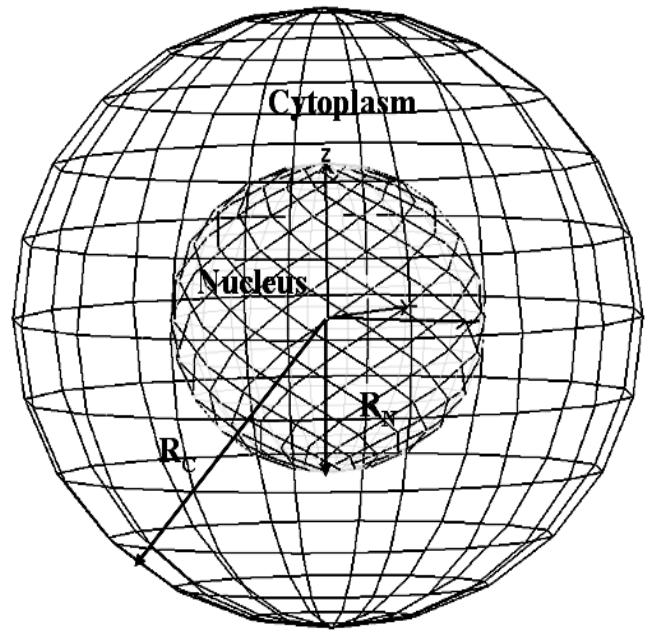

Fig. 1. 3D view of the cellular model.

A concentration of $20 \mathrm{kBq} . \mathrm{L}^{-1}$ of ${ }^{90} \mathrm{Sr}$ in drinking water was used and the femurs were obtained from 12-week-old mice.

For ${ }^{90} \mathrm{Sr}$ measurements, ${ }^{90} \mathrm{Sr}$ was mixed with stable $\mathrm{Sr}$ as a carrier in the proportion of 1:61. Six femurs were obtained from contaminated animals and two femurs were from control animals. In order to verify the presence of ${ }^{90} \mathrm{Sr}$ content in femur bone samples, the measurements were carried out by liquid scintillation counting, as previously described by Synhaeve et al. (2011).

However, for the microanalysis technique femurs were fixed in alcohol $70^{\circ}$, dehydrated in absolute alcohol then embedded in methyl methacrylate without prior decalcification (Boivin et al., 2010; Doublier et al., 2011).

\subsection{X-ray microanalysis}

\subsubsection{Cartography}

Six embedded bone samples were surfaced with an alumina suspension $(1 \mu \mathrm{m})$, carbon-coated, then fixed on the specimen holder (Boivin et al., 2010; Doublier et al., 2011).

$\mathrm{X}$-ray microanalysis was performed using a Camebax electron microprobe (Cameca, Gennevilliers, France) equipped with a Kevex Super Quantum Mark 5 energy-dispersive Xray spectrometer (Kevex Instruments, Valencia, CA, USA), coupled with the analysis system Noran Voyager III (Noran Instruments, Middleton, WI, USA).

$\operatorname{SrL} \alpha, \operatorname{PK} \alpha$ and $\operatorname{CaK} \alpha$ were analyzed on the same whole area of the femur bone sample, on a thickness of $1 \mu \mathrm{m}$ at a voltage of $15 \mathrm{kV}$. Secondary electron images (SEI) and X-ray images were performed for each sample. The resolution chosen for cartography was $256 \times 256$ pixels.

\subsubsection{Focal measurements}

The focal measurements were performed on $1 \mu \mathrm{m}^{2}$ areas. The areas analyzed included cortical and trabecular bone tissues. Six different measurements in each bone sample were carried out. 
Table 1. S-values for intracellular ${ }^{90} \mathrm{Sr}$.

\begin{tabular}{|c|c|c|c|c|c|c|c|}
\hline & & \multicolumn{2}{|c|}{$\mathbf{S}(\mathbf{N} \leftarrow \mathbf{N})(\mathbf{G y} / \mathbf{B q} \cdot \mathbf{s})$} & \multicolumn{4}{|c|}{$\mathrm{S}(\mathrm{N} \leftarrow \mathrm{Cy})(\mathrm{Gy} / \mathrm{Bq} . \mathrm{s})$} \\
\hline$\overline{\mathbf{R}_{C}(\mu \mathbf{m})}$ & $\overline{\mathbf{R}_{N}(\mu \mathbf{m})}$ & MIRD & $\mathrm{MC}$ & Relative deviation & MIRD & $\mathrm{MC}$ & Relative deviation \\
\hline 3 & 2 & $3.20 \times 10^{-3}$ & $3.13 \times 10^{-3}$ & $-2.1 \%$ & $1.04 \times 10^{-3}$ & $1.04 \times 10^{-3}$ & $+0.5 \%$ \\
\hline 4 & 3 & $1.39 \times 10^{-3}$ & $1.37 \times 10^{-3}$ & $-1.7 \%$ & $5.41 \times 10^{-4}$ & $5.54 \times 10^{-4}$ & $+2.4 \%$ \\
\hline 4 & 2 & $3.20 \times 10^{-3}$ & $3.14 \times 10^{-3}$ & $-2.0 \%$ & $6.55 \times 10^{-4}$ & $6.72 \times 10^{-4}$ & $+2.6 \%$ \\
\hline 5 & 4 & $7.68 \times 10^{-4}$ & $7.64 \times 10^{-4}$ & $-0.6 \%$ & $3.31 \times 10^{-4}$ & $3.41 \times 10^{-4}$ & $+2.9 \%$ \\
\hline 5 & 3 & $1.39 \times 10^{-3}$ & $1.36 \times 10^{-3}$ & $-1.9 \%$ & $3.80 \times 10^{-4}$ & $3.87 \times 10^{-4}$ & $+1.8 \%$ \\
\hline 5 & 2 & $3.20 \times 10^{-3}$ & $3.13 \times 10^{-3}$ & $-2.1 \%$ & $4.50 \times 10^{-4}$ & $4.60 \times 10^{-4}$ & $+2.2 \%$ \\
\hline 6 & 5 & $4.85 \times 10^{-4}$ & $4.85 \times 10^{-4}$ & $0.0 \%$ & $2.23 \times 10^{-4}$ & $2.28 \times 10^{-4}$ & $+2.2 \%$ \\
\hline 6 & 4 & $7.68 \times 10^{-4}$ & $7.64 \times 10^{-4}$ & $-0.6 \%$ & $2.48 \times 10^{-4}$ & $2.54 \times 10^{-4}$ & $+2.5 \%$ \\
\hline 6 & 3 & $1.39 \times 10^{-3}$ & $1.37 \times 10^{-3}$ & $-1.7 \%$ & $2.83 \times 10^{-4}$ & $2.87 \times 10^{-4}$ & $+1.4 \%$ \\
\hline 7 & 6 & $3.33 \times 10^{-4}$ & $3.33 \times 10^{-4}$ & $+0.1 \%$ & $1.60 \times 10^{-4}$ & $1.63 \times 10^{-4}$ & $+2.0 \%$ \\
\hline 7 & 5 & $4.85 \times 10^{-4}$ & $4.85 \times 10^{-4}$ & $-0.1 \%$ & $1.74 \times 10^{-4}$ & $1.79 \times 10^{-4}$ & $+2.9 \%$ \\
\hline 7 & 4 & $7.68 \times 10^{-4}$ & $7.63 \times 10^{-4}$ & $-0.6 \%$ & $1.94 \times 10^{-4}$ & $1.95 \times 10^{-4}$ & $+0.4 \%$ \\
\hline 7 & 3 & $1.39 \times 10^{-3}$ & $1.37 \times 10^{-3}$ & $-1.7 \%$ & $2.18 \times 10^{-4}$ & $2.25 \times 10^{-4}$ & $+3.2 \%$ \\
\hline 8 & 7 & $2.42 \times 10^{-4}$ & $2.43 \times 10^{-4}$ & $+0.4 \%$ & $1.20 \times 10^{-4}$ & $1.23 \times 10^{-4}$ & $+2.8 \%$ \\
\hline 8 & 6 & $3.33 \times 10^{-4}$ & $3.33 \times 10^{-4}$ & $+0.1 \%$ & $1.29 \times 10^{-4}$ & $1.32 \times 10^{-4}$ & $+2.0 \%$ \\
\hline 8 & 5 & $4.85 \times 10^{-4}$ & $4.84 \times 10^{-4}$ & $-0.1 \%$ & $1.41 \times 10^{-4}$ & $1.45 \times 10^{-4}$ & $+2.7 \%$ \\
\hline 8 & 4 & $7.68 \times 10^{-4}$ & $7.64 \times 10^{-4}$ & $-0.6 \%$ & $1.56 \times 10^{-4}$ & $1.58 \times 10^{-4}$ & $+1.5 \%$ \\
\hline 9 & 8 & $1.84 \times 10^{-4}$ & $1.85 \times 10^{-4}$ & $+0.5 \%$ & $9.37 \times 10^{-5}$ & $9.68 \times 10^{-5}$ & $+3.3 \%$ \\
\hline 9 & 7 & $2.42 \times 10^{-4}$ & $2.43 \times 10^{-4}$ & $+0.5 \%$ & $9.90 \times 10^{-5}$ & $1.02 \times 10^{-4}$ & $+2.9 \%$ \\
\hline 9 & 6 & $3.33 \times 10^{-4}$ & $3.33 \times 10^{-4}$ & $+0.1 \%$ & $1.07 \times 10^{-4}$ & $1.09 \times 10^{-4}$ & $+2.1 \%$ \\
\hline 9 & 5 & $4,85 \times 10^{-4}$ & $4.85 \times 10^{-4}$ & $-0.1 \%$ & $1.16 \times 10^{-4}$ & $1.20 \times 10^{-4}$ & $+3.2 \%$ \\
\hline 10 & 9 & $1.44 \times 10^{-4}$ & $1.45 \times 10^{-4}$ & $+0.9 \%$ & $7.49 \times 10^{-5}$ & $7.77 \times 10^{-5}$ & $+3.7 \%$ \\
\hline 10 & 8 & $1.84 \times 10^{-4}$ & $1.85 \times 10^{-4}$ & $+0.5 \%$ & $7.85 \times 10^{-5}$ & $8.10 \times 10^{-5}$ & $+3.1 \%$ \\
\hline 10 & 7 & $2.42 \times 10^{-4}$ & $2.43 \times 10^{-4}$ & $+0.3 \%$ & $8.37 \times 10^{-5}$ & $8.65 \times 10^{-5}$ & $+3.3 \%$ \\
\hline 10 & 6 & $3.33 \times 10^{-4}$ & $3.33 \times 10^{-4}$ & $0.0 \%$ & $9.02 \times 10^{-5}$ & $9.21 \times 10^{-5}$ & $+2.1 \%$ \\
\hline 10 & 5 & $4.85 \times 10^{-4}$ & $4.84 \times 10^{-4}$ & $-0.1 \%$ & $9.79 \times 10^{-5}$ & $1.01 \times 10^{-4}$ & $+2.8 \%$ \\
\hline
\end{tabular}

Focal X-ray microanalysis was performed using the same equipment previously mentioned above for cartography. $\operatorname{SrL} \alpha$, $\mathrm{PK} \alpha$ and $\mathrm{CaK} \alpha$ were analyzed at the same place at a voltage of $15 \mathrm{kV}$.

Each measurement represented a count of 100 seconds at the same place. For each element, contents were expressed as weight and atomic percentages $(100 \%$ corresponding to the total elements analyzed, i.e., $\mathrm{Ca}, \mathrm{P}, \mathrm{Sr}, \mathrm{Mg}, \mathrm{Na}$ and $\mathrm{O}$ ). Then, the weight and atomic ratios $\mathrm{Ca} / \mathrm{P}, \mathrm{Ca}+\mathrm{Sr} / \mathrm{P}, \mathrm{Sr} / \mathrm{Ca}, \mathrm{Sr} / \mathrm{P}$ and $\mathrm{Sr} / \mathrm{Ca}+\mathrm{Sr}$ were also calculated. Secondary electron images and X-ray images were performed to illustrate the focal $\mathrm{Sr}$ distribution in bone tissue.

\section{Results and discussion}

\subsection{S-factor comparison between MCNPX calculations and MIRD values}

Calculated S-values for the radii of the cell and cell nucleus ranging from 2 to $10 \mu \mathrm{m}$ and for two source-target combinations $(t \leftarrow s)$ : $\mathrm{N} \leftarrow \mathrm{N}$ and $\mathrm{N} \leftarrow \mathrm{Cy}$ are presented in Table 1. It was observed that $\mathrm{S}$-values decrease with increasing sphere size.

A comparison of MC results with those tabulated by the MIRD (Goddu et al., 1997) showed that the maximum relative deviations are less than $2.5 \%(2.1 \%)$ for $\mathrm{N} \leftarrow \mathrm{N}$ and less than $4 \%(3.7 \%)$ for $\mathrm{N} \leftarrow \mathrm{Cy}$ configurations.

The MC-calculated values are above those of the MIRD for the $\mathrm{N} \leftarrow \mathrm{Cy}$ configuration (when the ${ }^{90} \mathrm{Sr}$ source is localized in the cytoplasm) and mostly below MIRD values for the $\mathrm{N} \leftarrow \mathrm{N}$ configuration. We generally find the largest relative deviations with the MIRD, where the target is at some distance from the source. This can be caused by the electron penetration capability, which decreases with increasing sphere size.

A good agreement was shown between the S-values calculated with the MC code MCNPX and the MIRD values (Goddu et al., 1997), since the deviations are less than $4 \%$.

The overall uncertainty of the MCNPX calculations is difficult to estimate since it includes uncertainties in the crosssection. The standard statistical uncertainty in the calculations is less than $1 \%$. However, the standard deviation associated with the cellular S-value was not evaluated by the MIRD.

\section{2 ${ }^{90} \mathrm{Sr}$ detection in femur bone}

Table 2 presents the results of total Sr including ${ }^{90} \mathrm{Sr}$. The ${ }^{90} \mathrm{Sr}$ measurements were made with a $\beta$ counter on femur bone samples from mice receiving normal drinking water and water containing $20 \mathrm{kBq} . \mathrm{L}^{-1}$ of ${ }^{90} \mathrm{Sr}$. The detection limit of ${ }^{90} \mathrm{Sr}$ per bone sample was less than $1 \mathrm{~Bq}(0.50 \mathrm{~Bq})$. These early measured values seem to be relatively higher for female mice than male. The measurement results showed the presence of $\mathrm{Sr}$ in the femur bone.

\subsection{X-ray microanalysis: distribution and focal quantification of ${ }^{90} \mathrm{Sr}$ in bone cells}

To assess the impact of ${ }^{90} \mathrm{Sr}$ after exposure to lowdose ingestion in drinking water, remodeling bone areas was 
Table 2. Sr measurements, * Abbreviations used, F: female, M: male; DL: detection limit; n.a.: not applicable.

\begin{tabular}{ccccccc}
\hline Samples & Sex* & Group & Femur mass $(\mathbf{g})$ & $\begin{array}{c}{ }^{90} \text { Sr activity* } \\
(\mathbf{B q . g})\end{array}$ & $\begin{array}{c}{ }^{\mathbf{9 0}} \text { Sr activity } \\
\text { per femur }(\mathbf{B q})\end{array}$ & $\begin{array}{c}\text { Sr quantity } \\
\text { per femur* }(\mathbf{g})\end{array}$ \\
\hline a & F & Control & 0.0662 & $<$ DL & n.a. & n.a. \\
\hline b & F & Control & 0.0596 & $<$ DL & n.a. & \\
\hline c & F & Exposed & 0.0646 & 129.46 & 8.36 & $9.95 \times 10^{-11}$ \\
\hline d & F & Exposed & 0.0625 & 133.69 & 8.36 & $9.94 \times 10^{-11}$ \\
\hline e & M & Exposed & 0.0647 & 123.27 & 7.98 & $9.49 \times 10^{-11}$ \\
\hline f & M & Exposed & 0.0635 & 121.00 & 7.68 & $9.14 \times 10^{-11}$ \\
\hline
\end{tabular}
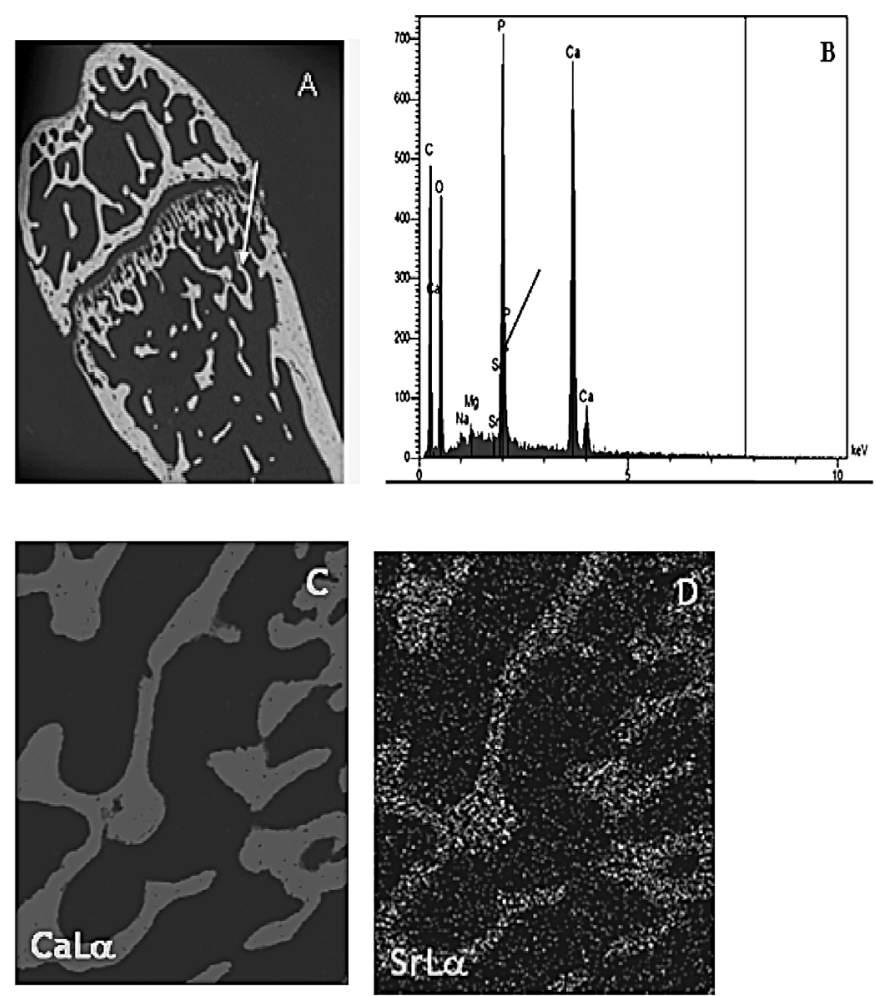

Fig. 2. (A) SEI of bone showing the femur bone morphology, bone trabeculae (arrow); (B) Microanalysis spectrum of bone, Sr peak (arrow); (C) Distribution of Ca in bone; (D) Distribution of $\mathrm{Sr}$ in bone, only background is detected.

investigated and we showed that the localization of ${ }^{90} \mathrm{Sr}$ was not evident in the bone structure such as cancellous or cortical bone cells. ${ }^{90} \mathrm{Sr}$ was below the detection limit $(<0.1 \%)$ in the bone samples (see Figs. 2B and 2D).

Under the experimental conditions used for this study, including the low concentration of ${ }^{90} \mathrm{Sr}$ in drinking water and period of intoxication, we were not able to find any evidence of the presence of ${ }^{90} \mathrm{Sr}$ in the bone samples.

This early observation could be explained by the very low intake of ${ }^{90} \mathrm{Sr}$-contaminated water.

Microanalysis is a complementary technique which permits identification and localization of elemental constituents in samples. However, this technique appears to be unsuitable since it allows a detection limit greater than 0.1 weight percent and requires a higher concentration of ${ }^{90} \mathrm{Sr}$ than that of the samples we examined.
Doublier et al. (2011) showed a distribution of the nonradioactive $\mathrm{Sr}$ in bone samples from postmenopausal woman treated with $2 \mathrm{~g} / \mathrm{d}$ of strontium ranelate for 60 months and investigated by $\mathrm{X}$-ray microanalysis.

For the present study it appears that the chemical measurements made with a $\beta$ counter can provide the lowest possible detection limit and therefore, this technique may yield meaningful results.

\section{Conclusions}

The comparison of the MC results with the MIRD values showed a good agreement since the relative deviations are less than $2.5 \%(2.1 \%)$ for $\mathrm{N} \leftarrow \mathrm{N}$ and less than $4 \%$ (3.7\%) for $\mathrm{N} \leftarrow \mathrm{Cy}$ configurations. MC simulations provide accurate data for use at the microscopic level and, as a consequence, improve the dosimetry at the (sub) cellular level of intracellular incorporated electron source-emitting radionuclides. Therefore, these results indicate that for the geometry used for this study, the use of the MCNPX is feasible and can reliably assess cellular dosimetry.

The earliest results of X-ray microanalysis indicated that the ${ }^{90} \mathrm{Sr}$ was below the detection limit $(<0.1 \%)$ in the bone tissue. The ${ }^{90} \mathrm{Sr}$ measurements made with a $\beta$ counter on femur bone samples showed the presence of ${ }^{90} \mathrm{Sr}$.

Low doses of ${ }^{90} \mathrm{Sr}$ radiation should continue to be investigated in order to predict more accurately the potential risks to human populations from the findings observed in laboratory animals.

Further experiments will be needed to localize the strontium in bone tissue. This study suggests that the strontium concentration in drinking water may be higher than that used in this work.

Acknowledgements. The expert assistance of Xavier Jaurand (Centre Technologique des Microstructures, Villeurbanne, Université de Lyon, France) and Hélène Follet (UMR 1033, Université de Lyon, France) was greatly appreciated.

\section{References}

Boivin G., Farlay D., Khebbab M.T., Jaurand X., Delmas P.D., Meunier P.J. (2010) In osteoporotic women treated with strontium ranelate, strontium is located in bone formed during treatment with a maintained degree of mineralization, Osteoporosis Int. 21, 667-677. 
Cooper E.L., Zeiller E., Ghods-Esphahani A., Makarewicz M., Schelenz R., Frindik O., Heilgeist M., Kalus W. (1992) Radioactivity in food and total diet samples collected in selected settlements in the USSR, J. Environ. Radioact. 17 (2-3), 147-157.

Cullen D.E., Hubbell J.H., Kissel L.D. (1997) EPDL97: the evaluated photon data library, 97 version. Report UCRL-50400, 6, Rev. 5. Lawrence Livermore National Laboratory.

Doublier A., Farlay D., Khebbab M.T., Jaurand X., Meunier P.J., Boivin G. (2011) Distribution of strontium and mineralization in iliac bone biopsies from osteoporotic women treated long-term with strontium ranelate, Eur. J. Endocrinol. 165 (3), 469-476.

Goddu S.M., Howell R.G., Bouchet L.G., Bolch W.E., Rao D.V. (1997) MIRD Cellular S Values (Reston, VA: Society of Nuclear Medicine).

ICRP (1993) Age-dependent doses to members of the public from intake of radionuclides: part 2. Ingestion dose coefficients. A report of a task group of committee 2 of the international commission on radiological protection, Ann. ICRP 23 (3-4), 1-167.

Pelowitz D.B. (Ed.) (2005) MCNPX User's Manual, Version 2.5.0. Los Alamos National Laboratory report LA-CP-05-0369 (April 2005).

Synhaeve N., Stefani J., Tourlonias E., Dublineau I., Bertho J.M. (2011) Biokinetics of ${ }^{90} \mathrm{Sr}$ after chronic ingestion in a juvenile and adult mouse model, Radiat. Environ. Biophys. 50, 501-511.

UNSCEAR (2011) Annex D: health effects due to radiation from the Chernobyl accident. Sources and effects of ionizing radiation. United Nations, New-York.

Weber D.A., Eckerman K.F., Dillman T., Ryman J.C. (1989) MIRD: radionuclide data and decay schemes. New York: Society of Nuclear Medicine.

Cite this article as: N. Hocine, D. Farlay, J.-M. Bertho, G. Boivin, A. Desbrée, D. Franck, M. Agarande. Cellular dosimetry of strontium-90 using the Monte Carlo code MCNPX, detection and X-ray microanalysis. Radioprotection 49(2), 101-105 (2014). 